\title{
Cannabis and benzodiazepines as determinants of methadone trough plasma concentration variability in maintenance treatment: a transnational study
}

\author{
Richard Hallinan - Séverine Crettol - Kingsley Agho • John Attia • Jacques Besson • \\ Marina Croquette-Krokar • Robert Hämmig • Jean-Jacques Déglon • Andrew Byrne • \\ John Ray • Andrew A. Somogyi • Chin B. Eap
}

Received: 24 October 2008 / Accepted: 20 June 2009 / Published online: 29 July 2009

(C) Springer-Verlag 2009

\begin{abstract}
Purpose To assess tobacco, alcohol, cannabis and benzodiazepine use in methadone maintenance treatment (MMT) as potential sources of variability in methadone pharmacokinetics. Methods Trough plasma (R)- and (S)-methadone concentrations were measured on 77 Australian and 74 Swiss MMT patients with no additional medications other than benzodiazepines. Simple and multiple regression analyses
\end{abstract}

Electronic supplementary material The online version of this article (doi:10.1007/s00228-009-0706-8) contains supplementary material, which is available to authorized users.

R. Hallinan · A. Byrne

The Byrne Surgery,

Redfern, NSW, Australia

S. Crettol · C. B. Eap

Unité de Biochimie et Psychopharmacologie Clinique, Centre des

Neurosciences Psychiatriques, Département de Psychiatrie-

CHUV, Hôpital de Cery, Université de Lausanne,

Prilly, Switzerland

\section{K. Agho}

School of Medicine, University of Western Sydney,

Sydney, NSW, Australia

\section{J. Attia}

Centre for Clinical Epidemiology and Biostatistics,

University of Newcastle,

Newcastle, NSW, Australia

J. Besson

Centre St-Martin, Département de Psychiatrie-CHUV,

Université de Lausanne,

Lausanne-Dorigny, Switzerland

M. Croquette-Krokar

Division d'Abus de Substances,

Hôpitaux Universitaire de Genève,

Geneva, Switzerland were performed for the primary metric, plasma methadone concentration/dose.

Results Cannabis and methadone dose were significantly associated with lower 24-h plasma $(R)$ - and $(S)$-methadone concentrations/dose. The models containing these variables explained $14-16 \%$ and $17-25 \%$ of the variation in $(R)$ - and $(S)$-methadone concentration/dose, respectively. Analysis of 61 patients using only CYP3A4 metabolised benzodiazepines showed this class to be associated with higher (R)concentration/dose, which is consistent with a potential competitive inhibition of CYP3A4.

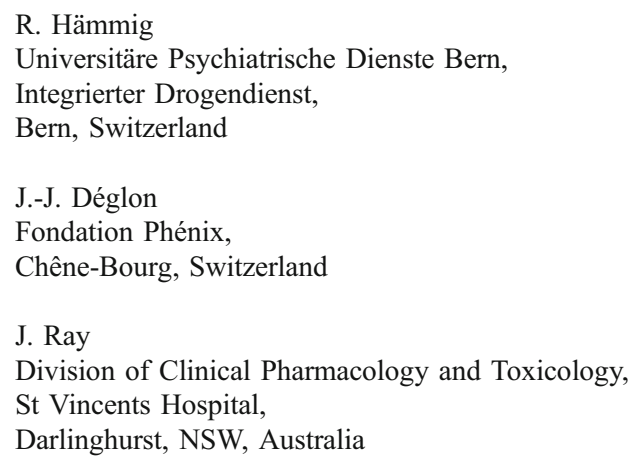

A. A. Somogyi

Discipline of Pharmacology, School of Medical Sciences,

University of Adelaide,

Adelaide, South Australia, Australia

C. B. Eap

Ecole de Pharmacie Genève-Lausanne, Université de Genève,

Université de Lausanne,

Geneva, Switzerland

C. B. Eap $(\square)$

Hôpital de Cery,

1008 Prilly, Switzerland

e-mail: chin.eap@chuv.ch 
Conclusion Cannabis use and higher methadone doses in MMT could in part be a response to-or a cause of - more rapid methadone clearance. The effects of cannabis and benzodiazepines should be controlled for in future studies on methadone pharmacokinetics in MMT.

Keywords Benzodiazepine - Cannabis · Drug interaction . Enantiomer $\cdot$ Methadone $\cdot$ MMT $\cdot$ Pharmacokinetics

\section{Introduction}

Methadone is the most widely used opioid replacement treatment for opiate dependency. It is usually given as a racemic mixture of $(R)$ - and $(S)$-methadone, with $(R)$ methadone accounting for most of the opioid effects.

Wide interindividual variability has been shown in the clinical pharmacokinetics of methadone [1]. A 17-fold variation was reported in plasma $(R)$-methadone concentration-to-dose ratios in patients taking no other medications, with a 41-fold variation among those taking other medications [2]. Interindividual variability in the function of cytochrome P450 (CYP) enzymes CYP2B6 and CYP3A4 may account for much of this variation and may be due to genetic polymorphisms and environmental factors, including the use of medications and non-prescribed substances [1,3]. $A B C B 1$ genetic polymorphisms, which encode for the permeability efflux transporter P-glycoprotein (P-gp), may also contribute to the interindindividual variability of methadone plasma and central nervous system pharmacokinetics [3, 4].

Methadone also displays large interindividual pharmacodynamic variability [1], with polymorphisms in the mu and delta opioid receptors and dopamine D2 receptors as possible candidates for this variability $[5,6]$.

While numerous studies have found high levels of alcohol, benzodiazepine, tobacco and cannabis use in subjects receiving methadone maintenance treatment (MMT) [7-16], there have been very few studies of pharmacokinetic interactions of these substances with methadone. Based on a study of MMT patients, Hallinan et al. [17] reported that benzodiazepine (mostly diazepam), but not alcohol, use was associated with lower plasma $(R)$ methadone concentration adjusted for dose and body weight $(p=0.001)$ in patients taking no other known medications. This result suggests that the use of some benzodiazepines may increase the clearance of methadone or be a response to increased inherent methadone clearance [17]. However this study did not examine cannabis or tobacco use. Other studies have found no acute effects of diazepam on methadone pharmacokinetics [18, 19], although diazepam has significant acute pharmacodynamic effects in methadone maintained patients [20, 21].
Diazepam could theoretically decrease the clearance of methadone by inhibiting CYP3A4 [22].

We have used an epidemiological approach to examine the hypothesis that tobacco, alcohol, cannabis and benzodiazepine use in MMT may be sources of methadone pharmacokinetic variability. The aim of our study was to assess the effect of concurrent use of tobacco, alcohol, cannabis and benzodiazepines on the 24-h trough plasma concentrations of methadone.

\section{Materials and methods}

The data used in this study was collected independently from MMT centers in Australia and Switzerland.

\section{Australian study group}

Data from the Australian study group have been previously reported elsewhere [23] and include MMT patients who had 24-h trough methadone concentration testing (their previous methadone dose supervised, a blood sample collected just before the next dose, with no dose change in the preceding 2 weeks) at the time of routine blood tests, which are done twice yearly. The study results reported here are derived from a subset of this group - those patients who were not taking any known medications other than methadone and benzodiazepines.

Current prescribed medications and substance use data were recorded at the time of pre-test or post-test counseling. Substance use data were recorded by the physician $(\mathrm{RH})$ as the Occasions of Drug Use Index (ODUI) [24] for the previous month, based on patient self-report with supportive evidence derived from the clinic protocol of regular medical consultations and urine toxicology. These occur generally every 1 to 4 weeks, depending on progress in treatment according to clinical indicators, including previous urine toxicology results. A physician is available to see patients whenever the clinic is open, such as when drug or alcohol use affects a patient's presentation. Positive urine tests do not lead to punitive actions, but they are indicators for more intensive engagement including more frequent urine tests.

Initial toxicology screening is carried out with an enzyme immunoassay (Microgenics CEDIA, Fremont, CA) for opiates, benzodiazepines and metabolites, cannabinoids, sympathomimetic amines, cocaine metabolites, barbiturates, with follow-up thin layer chromatography testing (Toxilab; Ansys Technologies, Lake Forest, CA) as required, including that for codeine, morphine/ monoacetylmorphine, amphetamine/methamphetamine and pseudoephedrine.

Collection of these data and their group-wise analysis for purposes of clinical audit and potential publication 
was reviewed by the Ethics Committee at Central Sydney Area Health Service (CSAHS Protocol $\mathrm{Nr}$ X04-0030 "Audit Activities at the Byrne Surgery"). All patients gave informed consent to urine and blood testing.

\section{Swiss study group}

Data from the Swiss study group have been previously reported elsewhere [3] and includes 276 patients in MMT at five methadone-dispensing centers in Geneva, Lausanne, Bern and Montreux (Switzerland). For the study reported here, patients who were not taking any known medications other than benzodiazepines were selected from among those who were receiving once daily methadone dosing and who also had a measured trough methadone concentration. Classification of current substance use status was by subject self-report of the frequency of use during the previous 3 -month period (never; up to $2 \times /$ week; $3 \times /$ week or more) in a confidential questionnaire. The only exception to this was the test for heroin and cocaine use, where classification was confirmed by the presence or absence of positive urines for opiates or cocaine metabolites over a period of 3 months prior to inclusion, with urine tests randomly performed at least once a week (this reflects the protocols of the original studies). Subjects were assured that no negative consequences would result from self report. Information on prescribed medications was available from the medical files of the patients. The study was approved by the local ethics committees of the participating centers, and written informed consent was obtained from all patients.

\section{Data}

Main outcome measures were trough plasma $(R)$ - and $(S)$ methadone concentration adjusted for methadone dose by dividing the plasma $(R)$ - and $(S)$-methadone concentration for each subject by their daily dose. This composite measure is widely used $[1,2]$ and has the benefit of being a better reflection of the bioavailability and clearance of methadone than unadjusted methadone concentrations, whereas adjustment for body weight is now accepted to be inappropriate $[23,25]$.

Other clinical data collected were: age, gender, body weight, body mass index (BMI), duration of current methadone treatment episode. Substance use data were treated as categorical variables, as follows:

- alcohol intake-exceeding or not exceeding low-risk drinking limits, i.e. $40 \mathrm{~g} /$ day or $280 \mathrm{~g} /$ week for men and $20 \mathrm{~g} /$ day or $140 \mathrm{~g} /$ week for women [26];

- smoking-current smokers and non-smokers of tobacco;
- cannabis use-current users and non-users (any use at all in reference period);

- heroin use - current users and non-users (any use at all in reference period);

- benzodiazepine use - those currently using benzodiazepines, whether prescribed or non-prescribed (any use at all in reference period; note patients taking zolpidem and zopiclone were excluded).

The periods of reference for alcohol, cannabis, heroin and benzodiazepine use were "last 30 days" for the Australian groups and "last 3 months" for the Swiss groups. The above limits for alcohol use were chosen as a convenient measure for dichotomizing alcohol consumption and have no particular significance for methadone metabolism or efficacy in MMT.

Analysis of $(R)$-methadone and $(S)$-methadone by high-performance liquid chromatography

For the Australian Study Group, plasma was separated from the blood samples within $4 \mathrm{~h}$, and the specimens were transported to the laboratory where they were frozen and stored at $-20^{\circ} \mathrm{C}$ until testing. Analysis of $(R)$-methadone and $(S)$-methadone was performed by high-performance liquid chromatography (HPLC) adapted from [28]. Calibration curves for $(R)$ and $(S)$-methadone were linear over the concentration range $20-1000 \mathrm{ng} / \mathrm{mL}$ with a coefficient of variance $(\mathrm{CV}) \leq 6.3 \%$. The limit of quantitation was $20 \mathrm{ng} / \mathrm{mL}$ with a $\mathrm{CV}>10.3 \%$ and deviation from the nominal value of less than $2.5 \%$.

For the Swiss study group, plasma was separated from the ethylenediaminetetraacetic acid-treated blood samples and the specimens stored at $-20^{\circ} \mathrm{C}$ until testing. Analysis of $(R)$-methadone and $(S)$-methadone was performed by liquid chromatography coupled with mass spectroscopy as previously described [27, 29, 30]. The method was fully validated over a concentration range of $5-800 \mathrm{ng} / \mathrm{mL}$ for each methadone enantiomer with satisfactory relative bias ( -1.0 to $1.0 \%)$, repeatability $(0.9-4.9 \%)$ and intermediate precision $(1.4-12.0 \%)$.

Data analysis

Simple and multiple regression analyses, including backward stepwise regression, were performed on both data sets separately for the effects of gender, age, months of treatment, daily methadone dose and use versus non-use of tobacco, alcohol, heroin, cannabis and benzodiazepines on outcome measures. Duration of treatment and daily dose were included as variables, owing to reports that methadone might induce its own metabolism at the beginning of treatment [25, 31, 32]. Multiple linear regression models 
were evaluated for normality of residuals and homogeneity of variance. Statistical analyses were undertaken with the statistical package STATA, ver. 8.2 and 9.2 (2004; Stata Corporation, College Station, TX). Statistical significance was taken as $P \leq 0.05$. Summary measures are presented as the mean \pm standard deviation (SD) for normally distributed data, and as the median with 25th and 75th percentiles for non-normally distributed data.

\section{Results}

Among the Australian study group, 77 of 158 patients receiving MMT between June and December 2003 met the inclusion criteria and were using no medications other than benzodiazepines and methadone, with blood samples taken at a mean $24.3 \mathrm{~h}(\mathrm{SD} 1.2 \mathrm{~h})$ after a witnessed dose. From the Swiss Study group, results were available for a total of 74 patients who were using no medications other than benzodiazepines and methadone: for all but eight of these patients there was no dose change in the 2 weeks preceding blood testing, and the minimum duration since the last dose change for these eight patients was 4 days. Blood samples were taken at a mean $23.3 \mathrm{~h}$ (SD $3.6 \mathrm{~h}$ ) after a witnessed dose.

Table 1 shows summary statistics for the two study groups. Recent cannabis, benzodiazepine and tobacco use were common in both study groups (for Australian and Swiss groups, respectively: 46 vs. $57 \%$; 36 vs. $46 \%$; 83 vs. $96 \%$ ), while alcohol use exceeding low-risk limits was more common in the Swiss group (38 vs. $16 \%$ ) and recent heroin was use less common (15 vs. 48\%). Prescribed diazepam was the benzodiazepine primarily reported by 14 of 28 benzodiazepine users in the Australian study group, with smaller numbers reporting use of prescribed alprazolam (one patient), oxazepam (two) and 11 patients reporting the use of whichever benzodiazepine was opportunistically available. This was most commonly diazepam, according to general patient report and the doctors' knowledge of benzodiazepine availability in the area, and less commonly oxazepam, alprazolam or clonazepam. A greater range of benzodiazepines used was reported from the Swiss study groups: oxazepam (11 patients), clonazepam (six), clorazepam (four), lorazepam (four), bromazepam (five), alprazolam (three), midazolam (four), diazepam (two), flurazepam (two), flunitrazepam (one) and triazolam (one).

Table 1 Demographic and plasma methadone concentrations summary statistics - dependent and independent variables for the Australian and Swiss study groups

\begin{tabular}{|c|c|c|}
\hline Variable & Australian Study Group $(n=77)$ & Swiss Study Group $(n=74)$ \\
\hline Duration of MMT, months ${ }^{\mathrm{a}}$ & $31(11-102)$ & $45(15-89)$ \\
\hline Age, years ${ }^{b}$ & $36.6(7.6)$ & $36.8(8.2)$ \\
\hline Weight, $\mathrm{kg}^{\mathrm{b}}$ & $72.9(14.5)$ & $75.2(15.7)$ \\
\hline Body mass index, $\mathrm{kg} / \mathrm{m}^{2 b}$ & $24.3(4.2)$ & $24.2(4.9)$ \\
\hline Methadone dose, mg/day ${ }^{\mathrm{a}}$ & $95(50-140)$ & $82.5(45,150)$ \\
\hline Time since previous supervised dose, $\mathrm{h}^{\mathrm{b}}$ & $24.3(1.2)$ & $23.3(3.6)$ \\
\hline Plasma $(R)$-methadone concentration, $\mathrm{ng} / \mathrm{mL}^{\mathrm{a}}$ & $160(85-229)$ & $166(91-281)$ \\
\hline Plasma $(R)$-methadone/dose, $\mathrm{ng} \times$ day $/ \mathrm{mL} \times \mathrm{mg}^{\mathrm{c}}$ & $1.8(0.7 ; 0.65-3.81)$ & $2.2(1.7 ; 0.6-12.8)$ \\
\hline Plasma (S)-methadone concentration, $\mathrm{ng} / \mathrm{mL}^{\mathrm{a}}$ & $138(80-190)$ & $157(89-254)$ \\
\hline Plasma $(S)$-methadone/dose $\left(\mathrm{ng} \times\right.$ day $/ \mathrm{mL} \times \mathrm{mg}^{\mathrm{c}}$ & $1.7(0.8 ; 0.4-4.1)$ & $2.1(2.0 ; 0.2-15.0)$ \\
\hline Plasma $(R, S)$-methadone concentration, $\mathrm{ng} / \mathrm{mL}^{\mathrm{a}}$ & $304(150-435)$ & $336(177-546)$ \\
\hline Plasma $(R, S)$-methadone/dose, $\mathrm{ng} \times \mathrm{x}$ day $/ \mathrm{mL} \times \mathrm{mg}^{\mathrm{c}}$ & $3.4(1.4 ; 1.1-7.9)$ & $4.3(3.7 ; 1.0-27.7)$ \\
\hline Plasma $(R) /(S)$-methadone ratio $^{c}$ & $1.1(0.3 ; 0.6-2.0)$ & $1.2(0.4 ; 0.7-3.4)$ \\
\hline Gender male (\%) & $60 / 77(77.9 \%)$ & $59 / 74(79.7 \%)$ \\
\hline Current cannabis use (\%) & $35 / 77(45.5 \%)$ & $42 / 74(56.8 \%)$ \\
\hline Current benzodiazepine use (\%) & $28 / 77(36.4 \%)$ & $34 / 74(46.0 \%)$ \\
\hline Exceeding low risk alcohol limits (\%) & $12 / 77(15.6 \%)$ & $28 / 74(37.8 \%)$ \\
\hline Tobacco smokers (\%) & $64 / 77(83.1 \%)$ & $71 / 74(96.0 \%)$ \\
\hline Current heroin use $(\%)$ & $37 / 77(48 \%)$ & $11 / 74(14.9 \%)$ \\
\hline
\end{tabular}

MMT, Methadone maintenance treatment; SD, standard deviation;

${ }^{\text {a }}$ Values are given as the median with 25 th and 75 th percentiles

${ }^{\mathrm{b}}$ Values are given as the means $\pm \mathrm{SD}$

${ }^{\mathrm{c}}$ Values are given as the mean with the SD and range given in parenthesis 


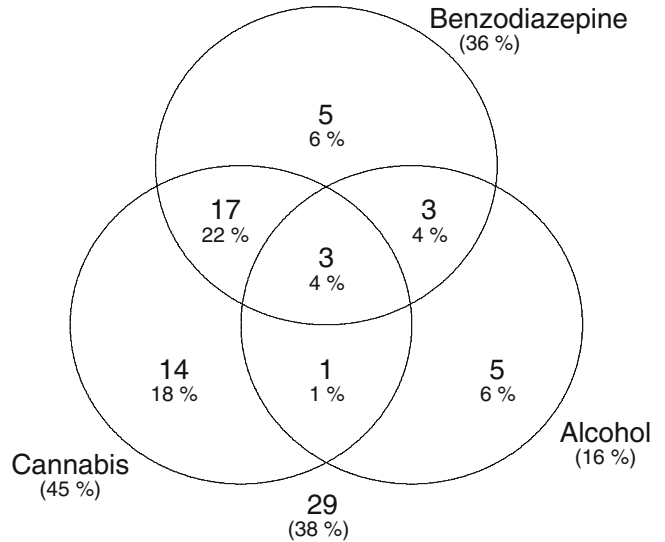

Fig. 1 Number and percentage of patients with benzodiazepine, cannabis and/or alcohol consumption in the Australian study group (29 patients did not use these substances)

As shown in Figs. 1 and 2, there was substantial overlap between benzodiazepine and cannabis use in the Australian group, and among benzodiazepine, alcohol and cannabis use in the Swiss group.

Lower 24-h trough plasma $(R)$-methadone concentration/ dose ratios were significantly associated with the following variables (Supplementary table): higher methadone dose (Australian group $R^{2}=0.072, P=0.019$; Swiss group $R^{2}=$ $0.072, P=0.021$ ); cannabis use (Australian group $R^{2}=$ $0.088, P=0.009$; Swiss group $R^{2}=0.087, P=0.011$ ); benzodiazepine use (Australian group only $R^{2}=0.060$, $P=0.032$ ); alcohol use (Swiss group only $R^{2}=0.059$, $P=0.037$ ); heroin use (Swiss group only $R^{2}=0.069$, $P=0.024)$.

Lower 24-h trough plasma $(S)$-methadone concentration/ dose ratios were significantly associated with the following (Supplementary table): higher methadone dose (Australian group $R^{2}=0.176, P<0.001$; Swiss group $R^{2}=0.103, P=$ 0.005); cannabis use (Australian group $R^{2}=0.076, P=$

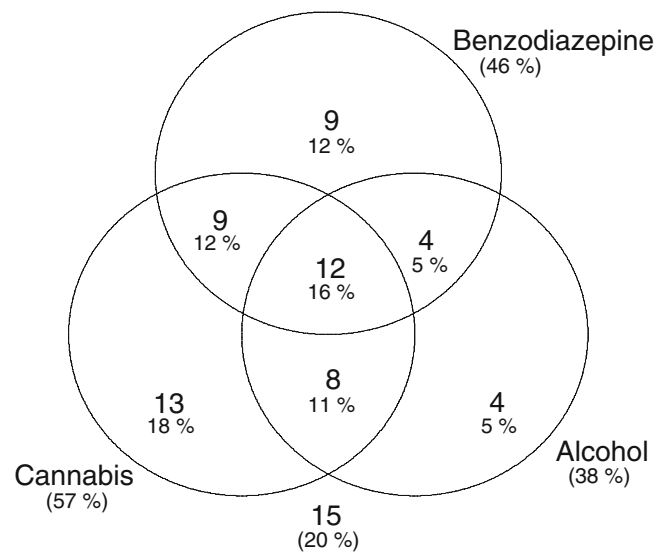

Fig. 2 Number and percentage of patients with benzodiazepine, cannabis and/or alcohol consumption in the Swiss study group (15 patients did not use these substances)
0.015; Swiss group $R^{2}=0.083, P=0.013$; heroin use (Australian group $R^{2}=0.0381, P=0.049$; Swiss group $R^{2}=0.063, P=0.032$ ); benzodiazepine use (Australian group only $R^{2}=0.099, P=0.005$ ); alcohol use (Swiss group only $\left.R^{2}=0.055, P=0.044\right)$. No significant associations were found between $(R)$ - or $(S)$-methadone concentration/dose ratios and duration of MMT, age, weight, BMI, gender or tobacco smoking in both groups (data not shown).

After backward stepwise regression (Table 2), cannabis and methadone dose remained significantly associated with lower 24-hour trough plasma $(R)$-methadone/dose and $(S)$ methadone/dose for both study groups. The models containing these variables explained 16 and $25 \%$ of the variation in plasma $(R)$ - and $(S)$-methadone/dose ratios, respectively, for the Australian study group and $14 \%$ and $17 \%$ for the Swiss study group.

An additional analysis was performed for the Swiss group after excluding those receiving oxazepam and lorazepam, which are mainly glucuronidated with no significant contribution of CYP3A4 in their metabolism. As shown in Table 2, cytochrome P450 metabolized benzodiazepines remained in the multivariate model for this group $(n=61)$, associated with higher trough plasma $(R)$-methadone/dose.

\section{Discussion}

After stepwise regression, cannabis use and higher daily methadone dose were found in both study groups to be significantly and negatively associated with 24-h trough $(R)$-methadone/dose and $(S)$ - methadone/dose; the latter were not associated with gender, alcohol, tobacco smoking or duration of MMT treatment. Multiple regression also revealed that body weight and BMI were unrelated to 24-h methadone concentration/dose, which is consistent with a previous report that methadone clearance is unrelated to body weight [25].

An association of higher methadone dose with lower methadone plasma concentration/dose ratio has been previously reported $[2,25]$ and may be explained by the induction of drug metabolism at higher methadone doses and/or saturation of plasma binding, which would lower the total plasma concentration/dose ratio without affecting unbound concentrations.

An association of cannabis use with lower plasma $(R)$-methadone/dose and $(S)$-methadone/dose has not been previously reported. One possible pharmacokinetic explanation could be induction of the isoenzyme CYP1A2 by smoke, leading to the increased metabolism of methadone; however, no association of tobacco smoking with trough methadone concentrations was found in our study nor in 
Table 2 Stepwise regression for $(R)$-methadone/dose and $(S)$-methadone/dose

\begin{tabular}{|c|c|c|c|c|c|c|}
\hline \multirow[t]{2}{*}{ Variable } & \multicolumn{3}{|c|}{ (R)-Methadone/dose (ng day/mL mg) } & \multicolumn{3}{|c|}{ (S)-Methadone/dose (ng day/mL mg) } \\
\hline & Coefficient (SE) & $P$ value & $95 \% \mathrm{CI}$ & Coefficient (SE) & $P$ value & $95 \% \mathrm{CI}$ \\
\hline \multicolumn{7}{|l|}{ Australian Study Group $(n=77)$} \\
\hline Methadone dose (mg/day) & $-0.003(0.001)$ & 0.015 & -0.005 to -0.001 & $-0.005(0.001)$ & $<0.001$ & -0.008 to -0.003 \\
\hline Cannabis (current users vs. non-users) & $-0.393(0.142)$ & 0.007 & -0.678 to -0.109 & $-0.431(0.160)$ & 0.009 & -0.750 to -0.112 \\
\hline \multirow[t]{2}{*}{ Constant } & $2.239(0.149)$ & 0.000 & $1.942-2.536$ & $2.411(0.167)$ & 0.000 & $2.077-2.744$ \\
\hline & \multicolumn{3}{|c|}{$\left(R^{2}=0.1582 ; P=0.002\right)$} & \multicolumn{3}{|c|}{$\left(R^{2}=0.2496 ; P<0.0001\right)$} \\
\hline \multicolumn{7}{|l|}{ Swiss Study Group $(n=74)$} \\
\hline Methadone dose (mg/day) & $-0.005(0.002)$ & 0.034 & -0.009 to -0.0004 & $-0.007(0.003)$ & 0.009 & -0.012 to -0.002 \\
\hline Cannabis (current users vs non-users) & $-0.931(0.382)$ & 0.017 & -1.693 to -0.169 & $-1.052(0.447)$ & 0.021 & -1.942 to -0.162 \\
\hline \multirow[t]{2}{*}{ Constant } & $3.259(0.367)$ & 0.000 & $2.527-3.992$ & $3.505(0.429)$ & 0.000 & $2.649-4.360$ \\
\hline & \multicolumn{3}{|c|}{$\left(R^{2}=0.1433 ; P=0.004\right)$} & \multicolumn{3}{|c|}{$\left(R^{2}=0.1680 ; P=0.002\right)$} \\
\hline \multicolumn{7}{|l|}{ Swiss Study Group $(n=61)^{\mathrm{a}}$} \\
\hline Methadone dose (mg/day) & $-0.007(0.003)$ & 0.012 & -0.013 to -0.002 & $-0.008(0.003)$ & 0.013 & -0.014 to -0.002 \\
\hline Cannabis (current users vs. non-users) & $-1.146(0.437)$ & 0.011 & -2.020 to -0.271 & $-1.213(0.524)$ & 0.024 & -2.263 to -0.164 \\
\hline Benzodiazepine (1) & $0.995(0.484)$ & 0.045 & $0.025-1.964$ & Not applicable ${ }^{\mathrm{b}}$ & & \\
\hline \multirow[t]{2}{*}{ Constant } & $3.352(0.428)$ & 0.000 & $2.495-4.209$ & $3.750(0513)$ & 0.000 & $2.723-4.776$ \\
\hline & \multicolumn{3}{|c|}{$\left(R^{2}=0.2070 ; P=0.004\right)$} & \multicolumn{3}{|c|}{$\left(R^{2}=0.1771 ; P=0.004\right)$} \\
\hline
\end{tabular}

CI, Confidence interval; SE, standard error

${ }^{\text {a }}$ Excluding users of oxazepam and lorazepam

${ }^{\mathrm{b}}$ Not significant in the multivariate analysis and therefore not included in the model

previous ones [3]. As the $A B C B 13435 T T$ genotype is associated with lower P-gp activity as well as slightly lower trough $(R, S)$-methadone plasma concentrations [3], another possible explanation involves P-gp inhibition by cannabinoids [33].

Alternatively, as the plasma methadone concentrationresponse relationship for withdrawal and mood symptoms is very steep $[34,35]$, cannabis use may be a compensatory response to opioid withdrawal symptoms in some individuals who have more rapid methadone clearance.

Contrary to data reported earlier by the Australian Study Group [17], subsequent multivariate analysis revealed no evidence of a relationship between benzodiazepine use and lower 24-h trough plasma methadone/dose. Although the Australian Study Group found that the most common benzodiazepine used was diazepam (according to patient report), patients can obtain benzodiazepines by visiting multiple doctors; in addition, benzodiazepines are readily available on the black market. Consequently, patients may use a range of benzodiazepines, depending on what is available. By contrast, the Swiss group generally used benzodiazepines prescribed by their methadone prescribing doctor, and analysis of the subgroup using CYP3A4 metabolized benzodiazepines showed this class to be associated with higher trough plasma $(R)$-methadone/dose, which is consistent with a potential competitive inhibition of CYP3A4.
The results for $(S)$-methadone/dose generally paralleled those for $(R)$-methadone/dose; however, the association of higher methadone dose with lower trough methadone concentration/dose was substantially stronger for $(S)$-methadone. Differences in the clearance of $(R)$ - and $(S)$ methadone may be of clinical importance as $(S)$-methadone has been incriminated in dysphoric effects at higher methadone doses [36] and shown to be a more potent hERG current inhibitor than $(R)$-methadone, with a higher risk for methadone-induced QT interval prolongation [37].

The limitations of this study should be mentioned. The validity of self-report measures of substance use may be questioned, with the potential systematic bias that MMT subjects may under-report their use of other substances. However, self-report of substances using populations has a high validity [38, 39], especially where honest selfreporting is encouraged without being linked to negative consequences [40, 41], as was true for both study groups described here. Self-report can reveal substance use not detected by urine analysis, which only detects recent use $[39,42,43]$. In a clinical setting, optimum results may be achieved by combining urine tests and self-reported drug use [44, 45], as occurs at the Australian Study Center and also partially at the Swiss Study Center.

The categorization of subjects as current users and nonusers of substances is rudimentary as it gives no indication of the amount or frequency of use. Cannabis use in 
particular is difficult to quantify, owing to the variety of methods of smoking and of the different potencies of the cannabis smoked. Allowing that MMT subjects may underreport their use of other substances and that information is lost in categorical classification, these factors would bias results towards the null, implying the significant associations of cannabis use identified in this study may be stronger in reality.

An inherent limitation of the epidemiological methodology of our study is that it is not capable of determining the causal direction of the associations found. It should also be noted that neither study group was selected to be representative of their respective MMT populations; differences in the univariate analyses for these groups may reflect different rates of alcohol and heroin use, or the differing methods and periods ( 1 vs. 3 months) of substance use assessment. However it is likely that, for most MMT patients, the use of benzodiazepines, cannabis and tobacco is relatively constant over such time frames.

The major strength of the study lies in its replication of findings in two independent and transnational study populations. These findings are all the more robust given the differences in the methods used by the Australian and Swiss groups to derive substance use data.

If the lower trough methadone concentrations/dose reported in this study actually do reflect methadone clearance, cannabis use and higher methadone doses in MMT may be either a response to-or cause of - more rapid methadone clearance. If the former, one would expect benzodiazepines, depending on their availability, to be used by patients in a similar way. However, we found no indication of this in our study. If the latter, the coefficients of variation $\left(R^{2}\right)$ on univariate analysis suggest that cannabis use may explain about $9 \%$ and methadone dose about $7 \%$ of the interindividual variation of the plasma $(R)$ methadone/dose ratio. Although in the cross-sectional analysis the scale of these associations is modest compared to the overall interindividual variation, their effects may be more substantial within individuals.

\section{Conclusion}

Cannabis use is common in MMT and may be considered by clinicians to be of minor importance. This study suggests the need for further experimental and clinical studies of the effects of cannabis on methadone pharmacokinetics. Future clinical studies of possible effects of benzodiazepines on methadone metabolism will require control for the effects of other substances, especially cannabis, and of the type of benzodiazepine used.

Acknowledgements Dr Andrew Somogyi's contribution to this study was supported by National Health and Medical Research Council of Australia (Project Grants no. 207710, 349537). The work in Switzerland was supported by the Swiss National Research Foundation (project 3200-065427.01) and Swiss Federal Office of Public Health (project 02.001382).

Conflicts of interest None

\section{Reference}

1. Eap CB, Buclin T, Baumann P (2002) Interindividual variability of the clinical pharmacokinetics of methadone: implications for the treatment of opioid dependence. Clin Pharmacokinet 41:11531193

2. Eap CB, Bourquin M, Martin JL, Spagnoli J, Livoti S, Powell K, Baumann P, Déglon JJ (2000) Plasma concentrations of the enantiomers of methadone and therapeutic response in methadone maintenance treatment. Drug Alcohol Depend 61:47-54

3. Crettol S, Déglon JJ, Besson J, Croquette-Krokkar M, Hämmig R, Gothuey I, Monnat M, Eap CB (2006) ABCB1 and cytochrome P450 genotypes and phenotypes: influence on methadone plasma levels and response to treatment. Clin Pharmacol Ther 80:668681

4. Coller JK, Barratt DT, Dahlen K, Loennechen MH, Somogyi AA (2006) ABCB1 genetic variability and methadone dosage requirements in opioid-dependent individuals. Clin Pharmacol Ther 80:682-690

5. Somogyi AA, Barratt DT, Coller JK (2007) Pharmacogenetics of opioids. Clin Pharmacol Ther 81:429-444

6. Crettol S, Deglon JJ, Besson A, Croquette-Krokar M, Hämmig R, Gothuey I, Monnat M, Preisig M, Eap CB (2008) Association of dopamine and opioid receptor gene polymorphisms with response to methadone during maintenance treatment. Prog Neuropsychopharmacol Biol Psychiatry 32:1722-1727

7. Brooner RK, King VL, Kidorf M, Schmidt CW Jr, Bigelow GE (1997) Psychiatric and substance use comorbidity among treatment-seeking opioid abusers. Arch Gen Psychiatry 54:71-80

8. Clemmey P, Brooner R, Chutuape MA, Kidorf M, Stitzer M (1997) Smoking habits and attitudes in a methadone maintenance treatment population. Drug Alcohol Depend 44:123-132

9. Bleich A, Gelkopf M, Schmidt V, Hayward R, Bodner G, Adelson M (1999) Correlates of benzodiazepine abuse in methadone maintenance treatment. A 1 year prospective study in an Israeli clinic. Addiction 94:1533-1540

10. Hillebrand J, Marsden J, Finch E, Strang J (2001) Excessive alcohol consumption and drinking expectations among clients in methadone maintenance. J Subst Abuse Treat 21:155-160

11. Asnafi-Farhang S, Hatchuel P, Bourhis F, Divine C, Lagrue G (2001) Prevalence of cannabis and tobacco use in patients attending a methadone center. Evaluation by urinary biomarkers. Ann Med Interne (Paris) 152[Suppl 3]:IS37-IS42

12. Backmund M, Meyer K, Henkel C, Soyka M, Reimer J, Schutz CG (2005) Co-consumption of benzodiazepines in heroin users, methadone-substituted and codeine-substituted patients. J Addict Dis 24:17-29

13. Weizman T, Gelkopf M, Melamed Y, Adelson M, Bleich A (2004) Cannabis abuse is not a risk factor for treatment outcome in methadone maintenance treatment: a 1-year prospective study in an Israeli clinic. Aust N Z J Psychiatry 38:42-46

14. Nahvi S, Richter K, Li X, Modali L, Arnsten J (2006) Cigarette smoking and interest in quitting in methadone maintenance patients. Addict Behav 31:2127-2134

15. Srivastava A, Kahan M, Ross S (2008) The effect of methadone maintenance treatment on alcohol consumption: a systematic review. J Subst Abuse Treat 34:215-223 
16. Stenbacka M, Beck O, Leifman A, Romelsjo A, Helander A (2007) Problem drinking in relation to treatment outcome among opiate addicts in methadone maintenance treatment. Drug Alcohol Rev 26:55-63

17. Hallinan R, Ray J, Agho K, Byrne A (2004) Correlations of $(R)$ methadone plasma concentrations in methadone maintenance (abstract). Presented the Australasian Professional Society on Alcohol and other Drugs (APSAD) Conference 2004. APSAD, Brisbane

18. Preston KL, Griffiths RR, Cone EJ, Darwin WD, Gorodetzky CW (1986) Diazepam and methadone blood levels following concurrent administration of diazepam and methadone. Drug Alcohol Depend 18:195-202

19. Pond SM, Tong TG, Benowitz NL, Jacob P III, Rigod J (1982) Lack of effect of diazepam on methadone metabolism in methadone-maintained addicts. Clin Pharmacol Ther 31:139-143

20. Spiga R, Huang DB, Meisch RA, Grabowski J (2001) Human methadone self-administration: effects of diazepam pretreatment. Exp Clin Psychopharmacol 9:40-46

21. Lintzeris N, Mitchell TB, Bond AJ, Nestor L, Strang J (2007) Pharmacodynamics of diazepam co-administered with methadone or buprenorphine under high dose conditions in opioid dependent patients. Drug Alcohol Depend 91:187-194

22. Iribarne C, Berthou F, Baird S, Dréano Y, Picart D, Bail JP, Beaune P, Ménez JF (1996) Involvement of cytochrome P450 3A4 enzyme in the $\mathrm{N}$-demethylation of methadone in human liver microsomes. Chem Res Toxicol 9:365-373

23. Hallinan R, Ray J, Byrne A, Agho K, Attia J (2006) Therapeutic thresholds in methadone maintenance treatment: a receiver operating characteristic analysis. Drug Alcohol Depend 81:129-136

24. Lawrinson P, Copeland J, Indig D (2005) Development and validation of a brief instrument for routine outcome monitoring in opioid maintenance pharmacotherapy services: the brief treatment outcome measure (BTOM). Drug Alcohol Depend 80:125-133

25. Foster DJR, Somogyi AA, White JM, Bochner F (2004) Population pharmacokinetics of $\left.{ }^{\mathbb{B}}\right)$-, $(\mathrm{S})$ - and rac-methadone in methadone maintenance patients. $\mathrm{Br} \mathrm{J}$ Clin Pharmacol $57: 742-755$

26. Commonwealth of Australia (2001) Australian alcohol guidelines: health risk and benefits. National Health and Medical Research Council, Australia

27. Crettol S, Déglon JJ, Besson J, Croquette-Krokkar M, Gothuey I, Hämmig R, Monnat M, Hüttemann $\mathrm{H}$, Baumann $\mathrm{P}$, Eap CB (2005) Methadone enantiomer plasma levels, CYP2B6, CYP2C19 and CYP2C9 genotypes, and response to treatment. Clin Pharmacol Ther 78:593-604

28. Rudaz S, Ortelli D, Gex-Fabry M, Deglon JJ, Balant L, Veuthey JL (1999) Development of validated stereoselective methods for methadone determination in clinical samples. Chirality 11:487-494

29. Souverain S, Eap CB, Veuthey JL, Rudaz S (2003) Automated LC-MS method for the fast stereoselective determination of methadone in plasma. Clin Chem Lab Med 41:1615-1621

30. Ansermot N, Rudaz S, Brawand-Amey M, Fleury-Souverain S, Veuthey JL, Eap CB (2009) Validation and long-term evaluation of a modified on-line chiral analytical method for therapeutic drug monitoring of ${ }^{\circledR}$, S)-methadone in clinical samples. J Chromatogr B 877:2301-2307

31. Änggàrd E, Gunne LM, Holmstrand J, McMahon RE, Sandberg C-G, Sullivan HR (1975) Disposition of methadone in methadone maintenance. Clin Pharmacol Ther 17:258-266

32. Nilsson MI, Änggàrd E, Holmstrand J, Gunne LM (1982) Pharmacokinetics of methadone during maintenance treatment: adaptive changes during the induction phase. Eur J Clin Pharmacol 22:343-349

33. Zhu HJ, Wang JS, Markowitz JS, Donovan JL, Gibson BB, Gefroh HA, DeVane CL (2006) Characterization of Pglycoprotein inhibition by major cannabinoids from marijuana. $\mathrm{J}$ Pharmacol Exp Ther 317:850-857

34. Dyer KR, Foster DJR, White JM, Somogyi AA, Menelaou A, Bochner F (1999) Steady-state pharmacokinetics and pharmacodynamics in methadone maintenance patients: comparison of those who do and do not experience withdrawal and concentration-effect relationships. Clin Pharmacol Ther 65:685-694

35. Dyer KR, White JM, Foster DJR, Bochner F, Menelaou A, Somogyi AA (2001) The relationship between mood state and plasma methadone concentration in maintenance patients. J Clin Psychopharmacol 21:78-84

36. Mitchell TB, Dyer KR, Newcombe D, Salter A, Somogyi AA, Bochner F, White JM (2004) Subjective and physiological responses among racemic-methadone maintenance patients in relation to relative $(S)$ - vs. $(R)$-methadone exposure. Br J Clin Pharmacol 58:609-617

37. Eap CB, Crettol S, Rougier JS, Schlapfer J, Sintra GL, Deglon JJ, Besson J, Croquette-Krokar M, Carrupt PA, Abriel H (2007) Stereoselective block of hERG channel by $(S)$-methadone and QT interval prolongation in CYP2B6 slow metabolizers. Clin Pharmacol Ther 81:719-728

38. Calhoun PS, Sampson WS, Bosworth HB, Feldman ME, Kirby AC, Hertzberg MA, Wampler TP, Tate-Williams F, Moore SD, Beckham JC (2000) Drug use and validity of substance use selfreports in veterans seeking help for posttraumatic stress disorder. $\mathrm{J}$ Consult Clin Psychol 68:923-927

39. Weiss RD, Najavits LM, Greenfield SF, Soto JA, Shaw SR, Wyner D (1998) Validity of substance use self-reports in dually diagnosed outpatients. Am J Psychiatry 155:127-128

40. Carroll KM (1995) Methodological issues and problems in the assessment of substance use. Psychol Assess 7:349-358

41. Babor TF, Brown J, DelBoca FK (1990) Validity of self-reports in applied research on addictive behaviors: fact or fiction? Behav Assess 12:5-31

42. Digiusto E, Seres V, Bibby A, Batey R (1996) Concordance between urinalysis results and self-reported drug use by applicants for methadone maintenance in Australia. Addict Behav 21:319-329

43. Magura S, Goldsmith D, Casriel C, Goldstein PJ, Lipton DS (1987) The validity of methadone clients' self-reported drug use. Int J Addict 22:727-749

44. Zanis DA, McLellan AT, Randall M (1994) Can you trust patient self-reports of drug use during treatment? Drug Alcohol Depend 35:127-132

45. Kilpatrick B, Howlett M, Sedgwick P, Ghodse AH (2000) Drug use, self report and urinalysis. Drug Alcohol Depend 58:111-116 